\title{
Re-use of aquaculture wastewater in cultivating microalgae as live feed for aquaculture organisms
}

\begin{abstract}
Culturing microalgae using commercial media is expensive. Proliferation of aquaculture is generating high amount of wastewater containing nitrogen and phosphorus and this could be a source of nutrient for cultivating microalgae thereby reducing the production costs. This study compared the growth, productivity, and proximate composition of Chaetoceros calcitrans, Nannochloris maculate, and Tetraselmis chuii cultured in aquaculture wastewater and Conway medium. Results indicated that selected microalgae cultivated in wastewater and Conway medium did not show any significant differences $(p>0.05)$ in terms of cell density, optical density, and biomass. Further, volumetric and areal productivity showed similar trend for all the three species. But lipid productivity (LP) in N. maculate was significantly higher ( $\mathrm{p}$ $<0.05)$ when cultured in wastewater medium compared to the Conway medium. There were no significant differences $(\mathrm{p}>0.05)$ for $\mathrm{C}$. calcitrans and T. chuii in terms of LP when cultivated in the two media. N. maculate and T. chuii had significantly higher $(\mathrm{p}<0.05)$ protein and lipid content compared to $\mathrm{C}$. calcitrans when cultured in wastewater medium. The three species did not show any significant differences $(p>0.05)$ in terms of carbohydrate content when cultured either in wastewater or Conway medium. The results indicate that aquaculture wastewater can be re-used as a possible source of low-cost nutrient for culturing selected microalgae for live feed utilization in aquaculture.
\end{abstract}

Keyword: Live feed; Microalgae; Proximate composition, productivity; Wastewater 